\title{
Choice and stimuli that signal reward
}

\author{
RONALD L. MENLOVE and FRED A. MASTERSON \\ University of Delaware, Newark, Delaware 19711
}

\begin{abstract}
Three pigeons pecked for food in a concurrent chain schedule. Pecks in both links of the concurrent chain produced the same rate and magnitude of access to food. Training consisted of two phases: In Phase 1, the two links were identical; in Phase 2, the availability of reward was signaled in one link. Initial link responding, averaged over the three birds, showed preference for the unsignaled link. The magnitude of preference depended upon the level of stimulus control in the terminal links. Subjects that responded differentially to the terminal links showed the highest level of choice. This result is different from previous studies, which have consistently shown preference for stimuli that signal reward.
\end{abstract}

Concurrent chain schedules have been used to show that animals prefer signaled to unsignaled reward (Fantino, 1977). In the classic experiment (Bower, McLean, \& Meacham, 1966), short and long fixedinterval (FI) schedules randomly alternated in each of the terminal links. One terminal link was unsignaled. However, in the second terminal link, one cue was presented during the short FI schedule, and a second cue was presented during the long FI schedule. Each of these two cues was presented from the onset of the terminal link until food was delivered. After food delivery, the subjects were returned to the initial links. The subjects consistently chose the signaled terminal link.

This observation has been used to conclude that whenever signaled reward is available, the situation in which reward is signaled will be preferred. For example, Wilkie (1973) presumed that when the availability of reward was signaled in one component of a multiple schedule, that component would be preferred. The purpose of the present experiment was to test Wilkie's assumption by using a concurrent chain schedule with terminal links similar to Wilkie's multiple-schedule components. Specifically, we will show that when reward is available, subjects will prefer a schedule with unsignaled reward to an otherwise identical schedule with signaled reward.

\section{METHOD}

\section{Subjects}

Three White Carneaux pigeons were maintained at $80 \%$ of their free-feeding body weights. These subjects had not been used in previous experiments. One subject, Bird 2, died during the course of the experiment.

\section{Apparatus}

The pigeons were trained in separate Lehigh Valley three-key experimental chambers. These chambers were interfaced to a laboratory computer. Each of the keys could be illuminated by an Industrial Electronics Engineers miniprojector with red, green, or white light. A white horizontal line could also be projected onto the center key.

\section{Procedure}

The pigeons were first trained to keypeck using an autoshaping procedure (Brown \& Jerkins, 1968). Thereafter, the pigeons responded on a two-component concurrent chain schedule. In this schedule, the pigeons were allowed simultaneous access to the two side keys in the initial link. Pecks on these side keys were intermittently followed by access to two terminal links. Aperiodically, pecks in either terminal link were followed by access to food.

Initial link. A synthetic concurrent schedule (Menlove, 1975 ) in the initial link arranged transition to the terminal links contingent upon sidekey pecks. The synthetic concurrent schedule parameters were arranged to simulate a concurrent variable-interval (VI) $60-\mathrm{sec} / \mathrm{VI} 60$-sec schedule. The minimum interreinforcement interval was $1 \mathrm{sec}$, the average initial link duration was $30 \mathrm{sec}$, and approximately half of the terminal link transitions were produced by each side key. A changeover delay prevented transition to the terminal links for $5 \mathrm{sec}$ following a change from one side key to the other. Both side keys were lighted white during the initial link, and the center key was dark.

Terminal links. Once a terminal link transfer had been arranged, a peck on the correct side key resulted in one of two terminal link stimuli. If a transfer was arranged on the left key, and the pigeons pecked on the left key, then the center key was lighted red, and the side keys became dark. If a transfer was arranged on the right key, and the pigeons pecked the right key, then the center key became green (except as described below), and the side keys became dark. Once a terminal link became effective, it remained in effect for $30 \mathrm{sec}$. In either terminal link, a synthetic VI 30 -sec schedule assigned the availability of reinforcement. A peck on the center key when reinforcement was available resulted in $2 \mathrm{sec}$ access to food. If no reinforcement was assigned during the 30 -sec terminal link presentation, then the terminal link was ended, and a new initial link began. If a reinforcement was assigned but not collected at the end of a terminal link, that reinforcement was available the next time that terminal link appeared. Each peck on a lighted key resulted in a 100-msec feedback blackout of all lights, including the houselight. Each daily session consisted of 30 cycles through the links of the concurrent chain.

Experimental conditions. The experiment was conducted in two phases. During Phase 1 , which served as a baseline for the study of choice, the two terminal links were identical except for the red and green colors that signaled them. Any preference between the two links of the concurrent chain schedules during this phase was interpreted as a key bias. Each subject was exposed to this phase of training for 20 daily sessions.

During Phase 2, the schedules were the same as in Phase 1, 
except that the availability of reinforcement was signaled in the green terminal link. That is, the terminal link accessed by a peck on the right side key was ordinarily associated with a green center key. However, when the VI 30 -sec schedule assigned a reinforcement, a white horizontal line was projected onto the green background of the center key. The first centerkey peck following the onset of the line was reinforced. Thus, the line served as a signal for the availability of reinforcement. Any preference between the two links of the concurrent chain schedule during Phase 2 was interpreted as a preference for or against signaled reinforcement. Each subject was exposed to this phase of training for 24 daily sessions.

Because differential responding in the terminal links was not well developed in all subjects during Phase 2, the entire procedure was replicated. In addition, the signal for the availability of reinforcement was changed in the replication in an attempt to improve stimulus control in the terminal links. Instead of displaying a white line on the green background, the entire center key became white. In all other respects, the procedure in the replication was the same as in original training. The same subjects were used in the replication. However, Bird 2 died from a gastrointestinal blockage during Phase 1 of the replication.

\section{RESULTS}

The means of the percentage of left-key pecks in the initial link are shown in Figure 1. These numbers are plotted as a function of successive 4-day blocks. The data points include the last 8 days of Phase 1 and all of Phase 2. These means are represented by the open circles in Figure 1, and they were obtained as

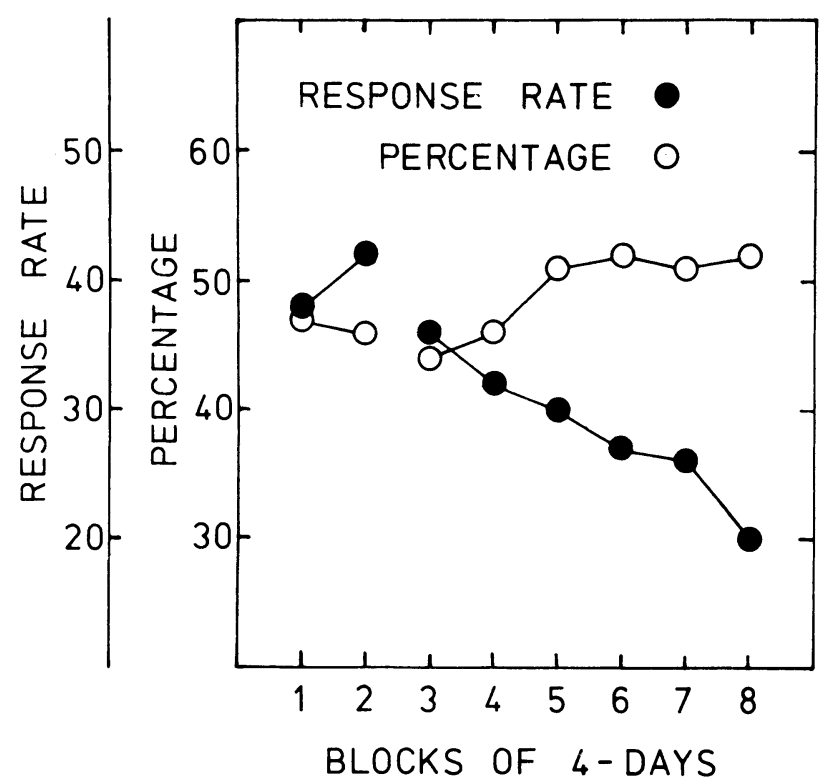

Figure 1. Average rate of terminal link responding and average percentage of initial link responding plotted against successive blocks of 4 days. The rate of response is shown by filled dots; the percentage of response is shown by open circles. The rate of responding is given in responses per component in the green terminal link and reflects stimulus control in the terminal links. The percentage of responding is given as the percentage of initial link responses on the left key and reflects preference for the unsignaled terminal link. follows. First, the number of left- and right-key pecks were counted for individual subjects in each daily session. Percentages were calculated from each of these pairs of numbers. Next, means and standard deviations were obtained on the percentages across 4-day blocks. The average standard deviation was .034 , and this number provides an estimate of within-block (withincondition) variability. Finally, means and standard deviations were obtained across subjects and replications. The means are shown in Figure 1. The average standard deviation was .106, which provides an estimate of between-subjects between-replications variability.

The mean number of responses per green terminal link cycle is also shown plotted as a function of successive 4-day blocks in Figure 1. These numbers are represented by closed dots. The means were obtained in the same manner as the percentages described above. The estimated within-block variability was 3.6 , and the estimated between-subject variability was 17.4.

The data in Figure 1 show that after subjects were exposed to Phase 2, there was a gradual decline in responding in the green terminal link. As responding in the green terminal link decreased, the subjects responded more often to produce the red terminal link. Thus, the subjects preferred unsignaled to signaled reinforcement. To substantiate the reliability of this observation, an analysis of variance was conducted on individual percentages comparing the last 8 days of Phase 1 with the last 8 days of Phase 2. This means that each subject (in each replication) contributed 16 numbers to the analysis. This analysis was used because different subjects showed different levels of stimulus control in the terminal links. Using multiple data points for each subject replication allowed the evaluation of Subject by Treatment interactions. The analysis of variance showed a reliable difference in preference between the two phases $[F(1,70)=27.68, p<.01]$. This difference was estimated to account for $6 \%$ of the variability in preference. The interaction between subjects and phases was also reliable $[F(4,70)=9.65, p<.01]$. This interaction was estimated to account for $8 \%$ of the variability in preference. Thus, there was an overall preference for the red terminal links in Phase 2. However, different subjects showed different levels of preference between the two phases.

Examining the individual subjects' data, it seemed clear that subjects that showed the largest decrease in green terminal link responding also showed the largest preference for the red terminal link. Thus, the level of preference in the initial link depended upon the level of stimulus control in the terminal links. To demonstrate this result, a correlation analysis was performed that related initial link percentages to response rate in the green terminal link. The simple correlation was reliable $[\mathrm{r}=-.62 ; \mathrm{F}(1,78)=48.7, \mathrm{p}<.01]$. These two variables were also partialed with respect to each of the other variables in the experiment, and the partial correlation 
was reliable $[\mathrm{pr}=-.13 ; \mathrm{F}(1,69)=8.8, \mathrm{p}<.01]$. Thus, preference for the red terminal link depended on the level of stimulus control in the terminal links.

\section{DISCUSSION}

The results of the present experiment show that there are contexts in which subjects prefer unsignaled to signaled reinforcement. In particular, when a cue for nonreward is presented until reinforcement is available, and then a cue signaling the availability of reward is presented, subjects prefer an unsignaled alternative. This context occurs, for example, when the availability of reinforcement is signaled in one component of a multiple schedule. Thus, the supposition that subjects always prefer signaled reinforcement is not appropriate. The value of signaled reinforcement in any context should be based on an empirical demonstration of choice in that context.

The demonstration that the value of signaled reward depends qualitatively on the context is consistent with previous demonstrations of intransitivity in concurrent chain schedules (Navarick \& Fantino, 1975). These studies suggest that the value of discriminative stimuli is multiply determined. Furthermore, some of the multiple determinants may contribute to a signal's information value, while others may contribute to the signal's conditioned reinforcer value, with the total value reflecting a combination of informational and conditioned reinforcement determinants. As a consequence, the debate over whether the value of discriminative stimuli is determined by the conditioned reinforcement value or the information value of the discriminative stimulus may be inappropriate.

\section{REFERENCES}

Bower, G., McLean, J., \& Meacham, J. Value of knowing when reinforcement is due. Journal of Comparative and Physiological Psychology, 1966, 62, 184-192.

Brown, P. L., \& Jenkins, H. M. Auto-shaping of the pigeon's key peck. Journal of the Experimental Analysis of Behavior, 1968, 11, 1-8.

Fantino, E. Conditioned reinforcement: Choice and information. In W. K. Honig \& J. E. R. Staddon (Eds.), Handbook of operant behavior. Englewood Cliffs, N.J: Prentice-Hall, 1977.

MeNLove, R. L. Local patterns of responding maintained by concurrent and multiple schedules. Journal of the Experimental Analysis of Behavior, 1975, 23, 309-337.

Navarick, D. J., \& Fantino, E. Stochastic transitivity and the unidimensional control of choice. Learning and Motivation, 1975, 6, 179-201.

Wilkie, D. M. Signalled reinforcement in multiple and concurrent schedules. Journal of the Experimental Analysis of Behavior, 1973, 20, 29-36.

(Received for publication December 5, 1979.) 